\title{
Event Ordering using TERSEO system
}

\author{
E. Saquete, R. Muñoz, P. Martínez-Barco \\ Grupo de investigación del Procesamiento del Lenguaje y Sistemas de Información. \\ Departamento de Lenguajes y Sistemas Informáticos. Universidad de Alicante. \\ Alicante, Spain
}

\begin{abstract}
In this paper, a method of event ordering based on temporal information resolution is presented. This method consists of two main steps: on the one hand, the recognition and resolution of the temporal expressions that can be transformed on a date, and therefore these dates establish an order between the events that contain them. On the other hand, the detection of temporal signals, for example after, that can not be transformed on a concrete date but relate two events in a chronological way. This event ordering method can be applied to Natural Language Processing systems, for example: Summarization, Question Answering, etc. It is important to emphasize that the event ordering method is based on a multilingual temporal information resolution system. Moreover, this multilinguality has been automatically obtained from a monolingual system (Spanish). The evaluation of the multilingual system is also shown in this paper, achieving a precision of $88 \%$ for Spanish and $77 \%$ for English.
\end{abstract}

Key words: temporal information, event ordering, temporal expressions, temporal recognition, temporal resolution, Natural Language Processing, Question Answering systems

\section{Introduction}

Today, the information society needs a set of tools for treating the increasing amount of digital information stored in the Internet. Document database applications help us to manage this information. However, document database

^ This paper has been supported by the Spanish government, project TIC-200307158-C02-01

Email address: \{stela,rafael, patricio\}@dlsi.ua.es (E. Saquete, R. Muñoz, P. Martínez-Barco). 
building requires the application of automatic processes in order to extract relevant information from texts.

One of these automatic processes is event ordering by means of temporal information. Usually, users need to obtain all the information related to a specific event. To do this, they must know the relationships between other events, and their chronological information. The automatic identification of temporal expressions associated with events, temporal signals that relate events, and further treatments of them, allows the building of their chronographic diagram. Temporal expressions treatment is based on establishing relationships between concrete dates or time expressions (25th December 2002) and relative dates or time expressions (the day before). Temporal signals treatment is based on determining the temporal relationship between the two events that the signal is relating. Using all this information, the application of event-ordering techniques allows us to obtain the desired event ordering. Moreover, event ordering can be applied to different tasks in the field of Natural Language Processing. Some of these tasks are Summarization, Question Answering, etc. In this paper, a method to apply Event Ordering to Temporal Question Answering has been developed.

Recently, the number of conferences related to temporal information extraction has been increased. It is necessary to emphasize the TERN 2004 conference, in which different temporal information extraction systems, including the system presented in this paper, have been evaluated.

This paper has been structured in the following way: first of all, section 2 gives a short introduction to the main contributions of previous work. Then, section 3 describes the Event Ordering system and the different components of the system: the Temporal Information Detection unit, the Temporal Expression Coreference Resolution unit, the Ordering Keys unit and the Event Ordering unit. Section 4 shows the extension of the monolingual system to a multilingual level. In section 5, the application of the event ordering method in one task of NLP (Question Answering) is explained. Finally, the evaluation of TERSEO system in Spanish and English and some conclusions are shown.

\section{Previous work}

At the moment, there are different kinds of systems that cope with the temporal information treatment and the event ordering issue. There are three different lines of work dealing with temporal information processing:

- Annotation of temporal information using schemes.

- Time-stamping. 
- Establishing relationships between events and/or temporal expressions in a text.

The most outstanding pieces of work for each one of these tasks are described in the following subsections.

\subsection{Temporal Annotation schemes}

An annotation scheme defines the guidelines for annotating entities in corpus with a canonicalized representation of them. Corpora entities annotated with a standard representation can be used by different applications in order to easily extract information. Our attention is focused on the schemes that annotate temporal entities since the temporal information is the one that we need to extract the chronology between the events.

The first approaches on temporal information recognition were presented at the Message Understanding Conferences (MUC). In particular, participants of MUC-5 and MUC-7 had to assign calendrical dates to certain types of events, and in addition, this information was not explicit, and that is why inferring information was required. After this, the most outstanding pieces of work in annotating temporal expression are: TIDES, STAG and TIMEML. These annotation schemes are explained in the following subsections.

\subsubsection{TIDES}

During the nineties, major efforts to develop an annotated corpus were made, in order to use them as a base for other applications. But, the first step was to define a standard annotation scheme. TIDES annotation scheme [1] arose with the purpose of annotating only temporal expressions in texts, under the support of the DARPA organization. Once the annotation had been done, the final aim was to use these annotated corpora in applications like Summarization, Question Answering, etc. TIDES defines a set of annotation guidelines for temporal expressions based on two basic principles:

(1) If a human can determine a value for the temporal expression, it should be tagged.

(2) The value of the expression must be based on internal evidence of the document that is being annotated.

The annotation process is divided into two main steps:

- Tagging of the temporal expressions in the text.

- Identifying the temporal value of the expression. 
The tag used in this scheme is TIMEX2 and it includes attributes for expressing the normalized, intended meanings or value of a broad range of temporal expressions. The set of attributes of this tag and their meaning are shown in Table 6 .

\subsubsection{STAG}

In addition to the TIDES annotation scheme, it is interesting to emphasize the annotation scheme presented by Setzer and Gaizauskas [2] [3], denominated STAG. STAG is a temporal annotation scheme that was developed at the University of Sheffield. It is oriented to the identification of events in news and the relationship of these events with points in a temporal line. Also it is able to annotate temporal signals and to relate one event to another one. TIDES, in contrast, only annotated temporal expressions.

\subsubsection{TIMEML}

In 2002, a new annotation scheme sponsored by the ARDA institution appeared. It was called TimeML [4]. TimeML is an annotation scheme to tag events, temporal expressions and the temporal relations between these events, combining and extending the features of both preceding schemes: TIDES and STAG. In addition, it added new features that made it a more powerful annotation scheme than TIDES and STAG, for instance, the relation of one event with more than one item in the text or the possibility that an event implies more than one action.

\subsection{Time-stamping}

When dealing with temporal information extraction some authors did not give as much importance to the precise annotation but to the aligning of some or all the events in a time-line assigning time marks to them. This process is called time-stamping and it involves, therefore, the solving of the temporal expressions associated to the events.

One of the systems based on time-stamping is the one by Filatova and Hovy [5] which describes a procedure for arranging into a time-line the contents of news stories describing the development of some situation. This approach describes a method for breaking news stories into their constituent events and assigning time-stamps to them. In order to assign time-stamps not only explicit references are resolved but also implicit ones. They consider that the syntactic units that denote events are simple clauses. The process of time-stamping in this method is: 
(1) The text is divided into event clauses.

(2) All date phrases in the text are extracted.

(3) A date is assigned to each event based on the most recent date phrase in the same sentences, or if there is no reference, the date of the article.

Another approach that it is interesting to highlight is the one made by Schilder and Habel [6]. This system detects temporal expressions and events and establishes temporal relationships between events. Temporal expressions are classified as:

- Expressions that denote dates.

- Expressions that denote events.

The final aim of this approach is to locate all these expressions in an absolute time-line in order to obtain a set of linear ordered temporal entities.

\subsection{Relationships between temporal information}

The works described in the previous sections were more focused on assigning a calendar date to temporal expressions or events in texts, but they are not taking into account temporal relations between these entities. The following works described address temporal relations directly.

The first approach is the one made by Katz and Arosio [7], that describes a method to annotate intrasentential temporal relations, that means, if in one sentence there is more than one event, the relationship between these events will be established. A temporal interval is associated with every event in the sentence and the relation between these intervals is the final aim. The possible relations are precedence $<$,inclusion $\subseteq$ and their correspondent duals $>$ and $\supseteq$. In order to establish these relations not only a syntactic annotation of the texts is used but also a semantic one.

However, this approach only considers relationships between the events of each sentence. Setzer and Gaizauskas [8] are focused on annotating EventEvent Temporal Relations in the whole text, using a time-event graph, which is able to keep more information than the approaches using a time-line. In the graph, nodes represent events or times and the edges represent temporal relations between the nodes. The main advantage of using a graph is that one event could not be related with a concrete date or time but with another event previously found due to the possibility of establishing relations between events and therefore, an order between the events. The problem with the graph is that it is costly.

Our proposal is a hybrid system (TERSEO) that combines the advantages of 
the systems explained before. TERSEO is a system that is able to recognize, resolve and annotate temporal information, and it uses this information to order the events in the text which means establishing a relationship between them. It had a knowledge database with all the expressions and their resolution rules that were only in Spanish at first, but an automatic acquisition of new rules for other languages has been developed [9] and this database has been extended to English as well. That is why TERSEO is able to work in a multilingual level. However, in this article we focus on the event ordering method based on TERSEO system. The description of the Event Ordering System is presented in the following section.

\section{Description of the Event Ordering System}

The schematic representation of the system proposed for event ordering is shown in Figure 1. Temporal information is detected in two steps. First of all, temporal expressions are obtained by the Temporal Expression Detection Unit. After that, the Temporal Signal Detection Unit returns all the temporal signals. The Temporal Expressions (TEs) that have been recognized are introduced into the resolution unit, which will update the value of the reference (document's date at first) according to the date it refers to and generates XML tags for each expression. These tags are part of the input of an event ordering unit. The temporal signals that have been obtained are introduced into a unit that obtains the ordering keys for each temporal signal. The ordering key establishes the order between two events and is used by the event ordering unit as well. With all this information the event ordering unit is able to return the ordered text. Temporal Expressions and Temporal signals are explained in detail below.

\subsection{Temporal Information Detection}

This work specializes or extends the work described in [10] for temporal expressions. For that, the Temporal Information Detection Unit is divided into two parallel steps:

- Temporal Expressions Detection

- Temporal Signal Detection

Both steps are fully explained in the following sections but they share a common preprocessing of the texts. Texts are tagged with lexical and morphological information by a Pos Tagger and this information is the input of a temporal parser. This temporal parser is implemented using an ascending technique 


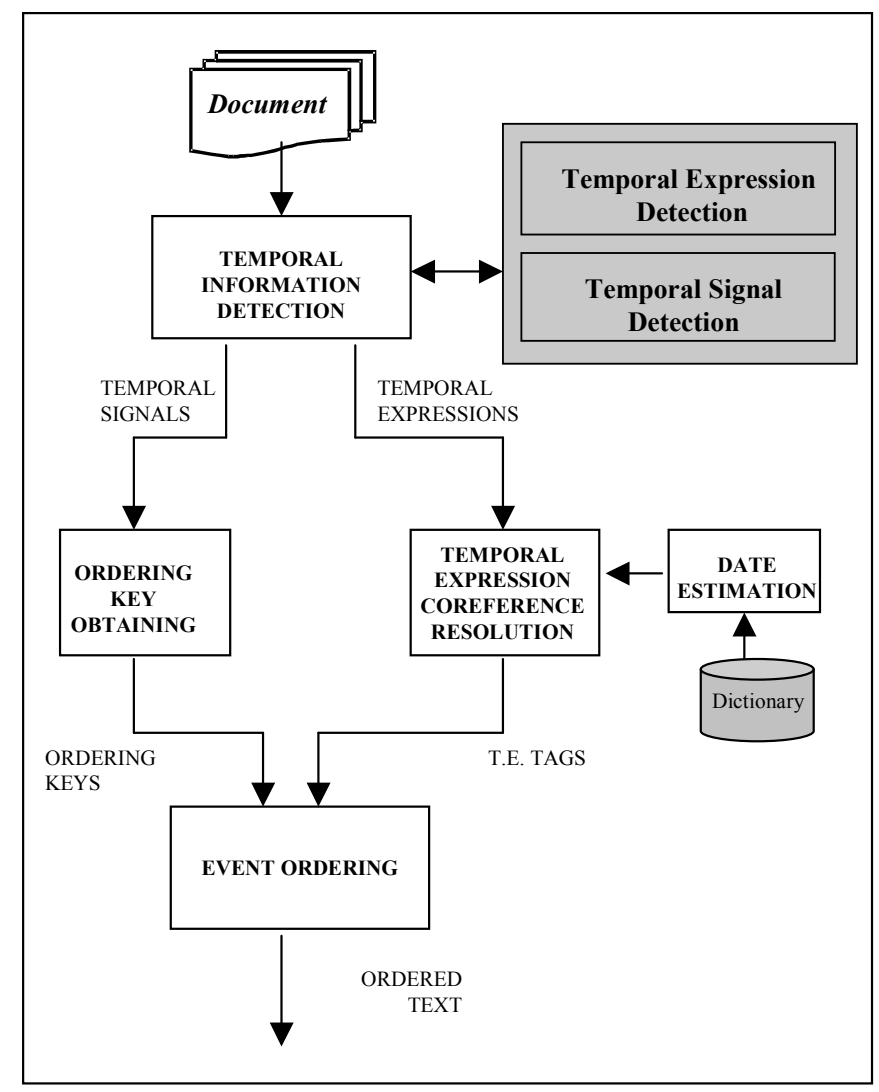

Figure 1. Graphic representation of the Event Ordering System

(chart parser) and it is based on a temporal grammar [11].

\subsubsection{Temporal Expressions Detection.}

In order to be able to recognize and resolve the temporal expressions, an initial task of classification of these expressions is needed, because the way of solving them depends on the type of expression. In this paper, two proposals for the classification of temporal expressions are shown. The first classification is based on the kind of reference. This classification is focused on recognizing the kind of expression when this enters the system and needs to be resolved.In addition, another type of classification is presented. This one is focused on the kind of output returned by the system for that type of expression.

\section{- Classification of the expression based on the kind of reference}

\section{- Explicit Temporal Expressions.}

Complete Dates with or without time expressions: "01/ 11/2002", "January 4th,2002", ...

Dates of Events:

Noun Phrase with explicit date: "2002-2003 course". In this expression, "course" denotes an event 
Noun Phrase with a well-known date: "Christmas", ...

\section{- Implicit Temporal Expressions.}

Expressions that refer to the Document date:

Adverbs or adverbial phrases: "yesterday", ...

Noun phrases: "the next month", ...

Prepositional phrases: "in the last month", ...

Expressions that refer to another date:

Adverbial Phrases: "during the course", ...

Noun Phrases: "a month later", "after next Christmas", ... For example, with the expression "after next Christmas" it is necessary to resolve the TE "next Christmas" and then apply the changes that the word "after" makes on the date obtained.

Prepositional Phrases: "from Christmas" , "since last Christmas", ...

- Classification by the representation of the temporal value of the expression

- Concrete. All those that give back a concrete day and/or time with format: mm/dd/yyyy (hh:mm:ss), for example: "yesterday".

- Period. All those expressions that give back a time interval or range of dates: [mm/dd/yyyy-mm/dd/yyyy], for example: "during the five following days".

- Fuzzy. It gives back an approximate time interval because it does not know the concrete date that the expression refers to. There are two types:

Fuzzy concrete. If the given result is an interval but the expression refers to a concrete day within that interval, and we do not know it accurately. For that reason we must give back the approach of the interval, for example: "one day last week", ...

Fuzzy period. If the expression refers to an interval contained within the given interval, for instance: "some days before", "for weeks", ...

Section 5 shows how the system is able to solve a great part of these temporal expressions, that have been recognized by the Temporal Expression Unit.

\subsubsection{Temporal Signals Detection.}

The temporal signals relate the different events in texts and establish a chronological order between these events. In an experimental way, after the study of a training corpus, a set of temporal signals has been obtained, and some of them are emphasized here: after, when, before, during, previously, from ... to ..., on, in, while, for, at the time of, since,etc. 


\subsection{Temporal Expression Coreference Resolution}

Temporal Expression Coreference Resolution is organized in two different tasks:

- Anaphoric relation resolution based on a temporal model

- Tagging of temporal Expressions

Each task is subsequently explained.

\subsubsection{Anaphoric relation resolution based on a temporal model.}

The anaphoric resolution of the TE's is made following the same strategies for anaphora resolution that in $[12,13,14]$.These strategies consist on looking for the most suitable antecedent. For the anaphoric relation resolution we use an inference engine that interprets every reference named before. In some cases the references are estimated using the document date (FechaP). Others refer to a date named before in the text that is being analyzed (FechaA). For these cases, a temporal model that allows us to know on what date the dictionary operations are going to be done, is defined. This model is based on the two rules below and it is only applicable to those dates that are not FechaP, since for FechaP there is nothing to resolve:

(1) By default, the newspaper date is used as a base referent (TE) if it exists, if not, the system date is used.

(2) If a non-anaphoric TE is found, this is stored as FechaA. This value is updated every time a non-anaphoric TE appears in the text.

In Table $1^{1}$ some of the entries in the dictionary used in the inference engine are shown. The unit that makes the estimation of the dates will accede to the right entry in the dictionary in each case and it will apply the function specified obtaining a date in the format $\mathrm{mm} / \mathrm{dd} /$ yyyy or a range of dates. So, at that point the anaphoric relation will have been resolved.

\subsubsection{Tagging of temporal expressions.}

Several proposals for the annotation of TEs have arisen in the last few years Wilson et al. [15], Katz and Arosio [7], TIMEML [4], etc. since some research

1 The operation ' +1 ' in the dictionary is able to interpret the dates in order to give back a valid date. For example, if the Month (date) function gives back 12 and the operation ' +1 ' is done on that value, the given back value will be 01 , increasing a year. 


\begin{tabular}{|c|c|}
\hline REFERENCE & DICTIONARY ENTRY \\
\hline 'yesterday' & Day (FechaP)-1/Month (FechaP)/Year (FechaP) \\
\hline 'tomorrow' & $\operatorname{Day}($ FechaP $)+1 /$ Month (FechaP) /Year (FechaP) \\
\hline \multirow[t]{2}{*}{ 'during the following month' } & [DayI/Month $($ FechaA $)+1 /$ Year $($ FechaA $)--$ \\
\hline & $\operatorname{DayF} / \operatorname{Month}($ FechaA $)+1 / \operatorname{Year}($ FechaA $)]$ \\
\hline \multirow[t]{2}{*}{ num+'years later' } & {$[01 / 01 /$ Year $($ FechaA $)+$ num -- } \\
\hline & 31/12/Year $($ FechaA $)+$ num $]$ \\
\hline 'a day before' & $\operatorname{Day}($ FechaA $)-1 / \operatorname{Month}($ FechaA $) /$ Year (FechaA) \\
\hline 'some days later' & $\gg \gg$ FechaA \\
\hline 'some days before' & $<<<<$ FechaA \\
\hline
\end{tabular}

Table 1

Sample of some of the entries in the dictionary

institutions have started to work on different aspects of temporal information. In this section, our own set of XML tags is defined in order to standardize the different kinds of TEs. We have defined a simple set of tags and attributes that adjust to the necessities of our system, without complicating it. Besides, they could be transformed to other existing formats, like TIMEML, at any time. These tags show the following structure:

- For Explicit Dates:

<DATE_TIME ID="'value', TYPE=" value", VALDATE1=" "value" '

VALTIME1 = "value", VALDATE2=" "value" VALTIME2=" "value" '

VALORDER=" 'value' '>expression</DATE_TIME $>$

- For Implicit Dates:

<DATE_TIME_REF ID=" value", TYPE=" value', VALDATE1=" value" '

VALTIME1=" "value" VALDATE2=" "value" VALTIME2= "value" '

VALORDER= ' $v a l u e$ ' ' $>$ expression</DATE_TIME_REF $>$

DATE_TIME is the name of the tag for explicit TEs and DATE_TIME_REF is the name of the tag for implicit TEs. Every expression has a numeric ID to be identified and VALDATE\# and VALTIME\# store the range of dates and times obtained from the inference engine, where VALDATE2 and VALTIME2 are only used to establish ranges. Also, VALTIME1 could be omitted if only a date is specified. VALDATE2, VALTIME1 and VALTIME2 are optional args. VALORDER is the attribute where the event ordering unit will specify the ordering value, at first there is no value for this attribute. After that, a structured document is obtained. The use of XML allows us to take advantage of the XML schema in which the tag language is defined. This schema lets an application know if the XML file is valid and well-formed. A parser of our XML needs to be defined to make the information useful. 


\subsection{Ordering Keys Obtaining}

The temporal signals obtained by the Temporal Signal Detection Unit are used by this unit to obtain the ordering keys. The study of the corpus revealed a set of temporal signals. Each temporal signal denotes a relationship between the dates of the events that it is relating. For example, in EV1 S EV2, the signal S denotes a relationship between EV1 and EV2. Assuming that F1 is the date related to the first event and F2 is the date related to the second event, the signal will establish a certain order between these events. This order will be established by the ordering unit. Some of the ordering keys, which are the output of this unit, are shown in Table 2.

\begin{tabular}{|l|l|}
\hline SIGNAL & ORDERING KEY \\
\hline After & DATE1 $>$ DATE2 \\
\hline When & DATE1 $=$ DATE2 \\
\hline Before & DATE1 $<$ DATE2 \\
\hline During & DATE2 $i<=$ DATE1 <= DATE2f \\
\hline Previously & DATE1 $>$ DATE2 \\
\hline From DATE2 to DATE3 & DATE2 $<=$ DATE1 $<=$ DATE3 \\
\hline About DATE2 - DATE3 & DATE2 $<=$ DATE1 $<=$ DATE3 \\
\hline On $/$ in & DATE1 $=$ DATE2 \\
\hline While & DATE2 $i<=$ DATE1 $<=$ DATE2f \\
\hline For & DATE2 $i<=$ DATE1 <= DATE2f \\
\hline At the time of & DATE1 $=$ DATE2 \\
\hline Since & DATE1 $>$ DATE2 \\
\hline \hline
\end{tabular}

Table 2

Output of the ordering Key Obtaining Unit

\subsection{Event ordering method}

Event ordering in natural language written texts is not a trivial task. Firstly, a process to identify events must be carried out. Then, the relationship between the events or between the event and the date when the event occurs must be identified. Finally, the ordering of events must be determined according to their temporal information. This temporal information could be dates, temporal expressions or temporal signals. We have trivialized the task of identifying 
events. We will only identify events of a sentence that includes some kind of TE or a sentence that is related to another sentence by a temporal signal.

Using the XML tags and the ordering keys, the event ordering module runs over the text building a table that specifies the order and the dates, if there are any, of every event. The order is established according to the following rules:

(1) EV1 is previous to EV2:

- if the range of VALDATE1, VALTIME1, VALDATE2, VALTIME2 associated with EV1 is prior to and not overlapping the range associated with EV2.

- or, if the ordering key that relates both events is: EV1<EV2

(2) EV1 is concurrent to EV2:

- if the range of VALDATE1, VALTIME1, VALDATE2, VALTIME2 associated with EV1 overlaps the range associated with EV2.

- or, if the ordering key that relates both events is:

EV1=EV2 or EV1i<=EV2<=EV1f

The system will assign a sequential order number to every event in the table, having the same order number for concurrent events.

In Figure 2 an example is shown. Newspapers date: 30/12/2002

\subsection{Implementation of the system}

TERSEO $^{2}$ system is a web application that has been developed in php language, using a MySQL database in order to store the different temporal expressions and resolution rules. In order to show the different steps of the multilingual system developed, an example has been performed using a Spanish article as input.

Figures 3, 5, 4 y 6 are showing the different steps for the example provided. In the first step (Figure 3), it is necessary to introduce the newspaper date, the language of the article and the file with the article. Once all the inputs are introduced, there are two possibilities: Recognition and resolution or only Resolution.

Figure 4 is showing the results when only Resolution is performed. Figure 5 is showing the results when Recognition and Resolution is performed. At the top of the screenshot the recognition of the temporal expressions within the

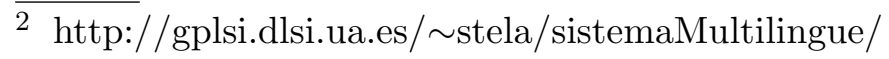




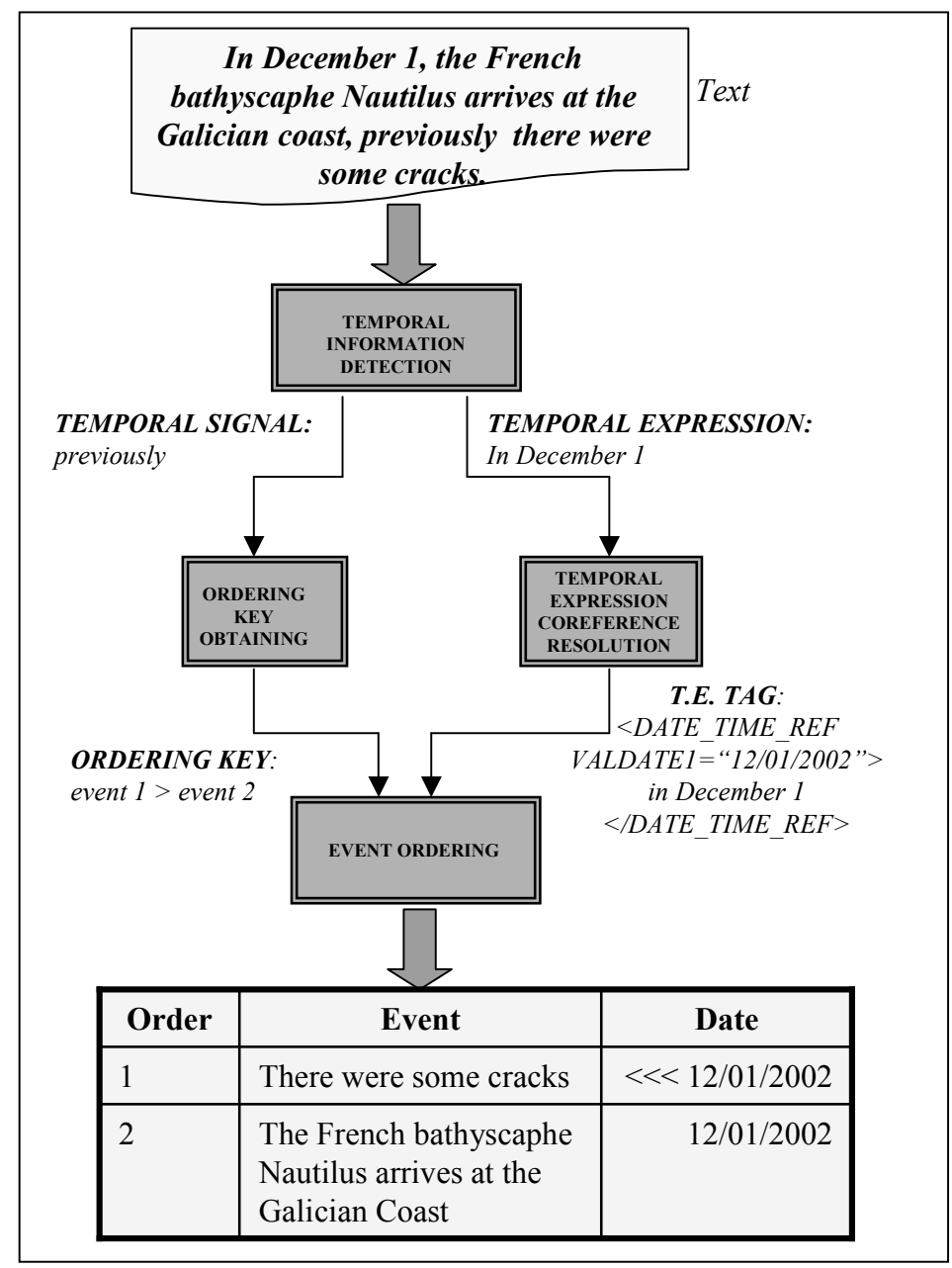

Figure 2. Graphical example of Event Ordering

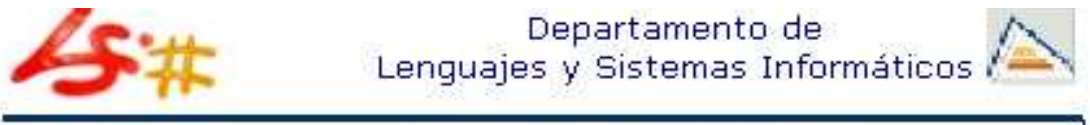

TERSEO MULTILINGUE

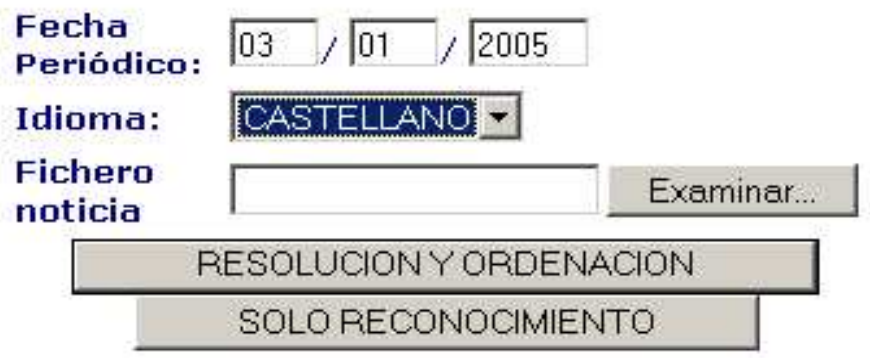

Figure 3. First step TERSEO

article is presented and at the bottom the result of the resolution of these expressions is shown. 


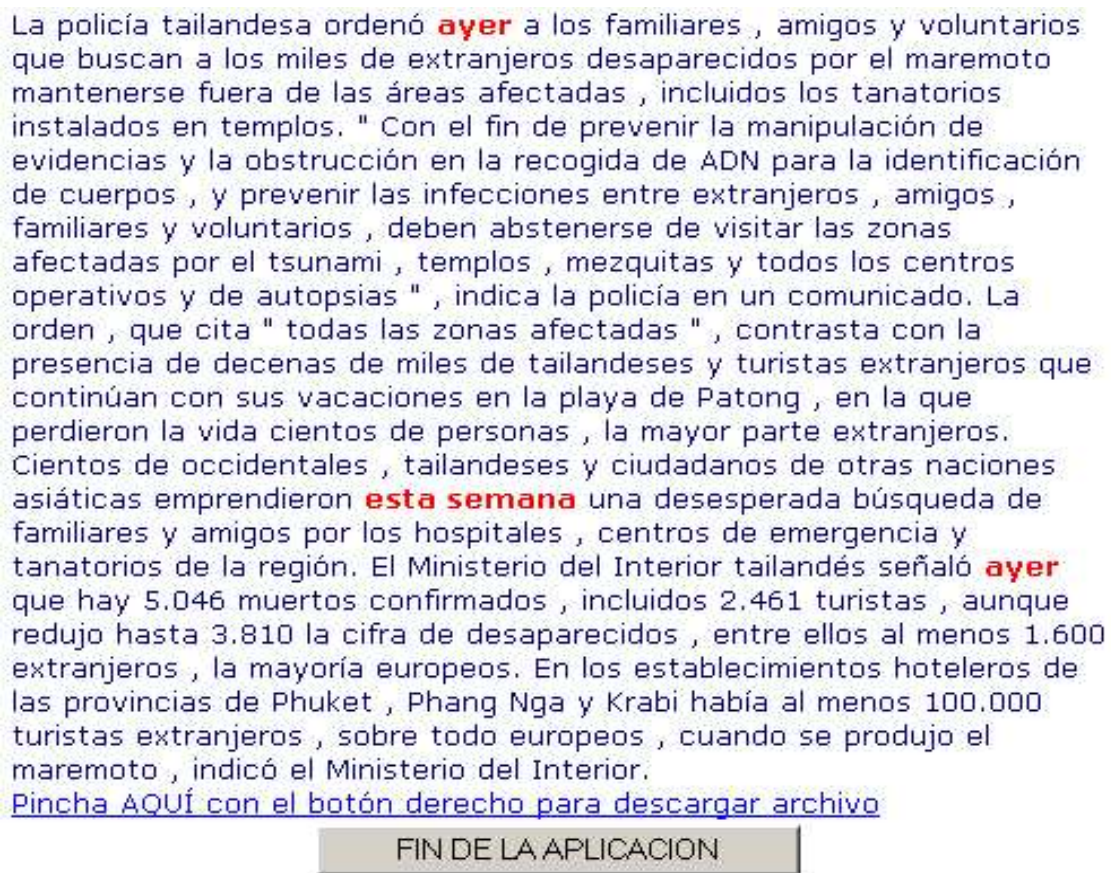

Figure 4. TERSEO: Only Resolution

Finally, Figure 6 is showing the event ordering performed, assigning a order number to each event in the article.

\section{Multilinguality}

The system explained before was a monolingual system that at first used a hand-made knowledge database in Spanish. Our main goal was the possibility of working with TERSEO on a multilingual level, but building the different knowledge databases for the new languages through the automatic acquisition of rules [9]. With the automatic acquisition of rules it is possible to create a multilingual system with no need of a previous knowledge of the other languages to which TERSEO system is going to be extended. For this purpose, an architecture similar to the one used by WordNet [16] was proposed, to obtain knowledge databases for the different languages, but all of them are connected though a unit denominated TER-ILI or Temporal Expression Rules Interlingua Index which is shown in Figure 7. In doing that, TERSEO system could have a new knowledge database for each new language and be able to solve any expression in this language, also the system would be easily extensible to other new languages. At first, we only had the Knowledge Database for Spanish, linked to rules in the TER-ILI unit but now the system has been extended to English and we aim to have every Knowledge Database (English, German, French, ...) linked to TER-ILI as well as a further work. 
La policía tailandesa ordenó \$ayer a los familiares, amigos y voluntarios que buscan a los miles de extranjeros desaparecidos por el maremoto mantenerse fuera de las áreas afectadas, incluidos los tanatorios instalados en templos. " Con el fin de prevenir la manipulación de evidencias y la obstrucción en la recogida de ADN para la identificación de cuerpos, y prevenir las infecciones entre extranjeros, amigos, familiares y voluntarios, deben abstenerse de visitar las zonas afectadas por el tsunami, templos, mezquitas y todos los centros operativos y de autopsias " , indica la policía en un comunicado. La orden, que cita " todas las zonas afectadas" , contrasta con la presencia de decenas de miles de tailandeses y turistas extranjeros que continúan con sus vacaciones en la playa de Patong, en la que perdieron la vida cientos de personas, la mayor parte extranjeros. Cientos de occidentales, tailandeses y ciudadanos de otras naciones asiáticas emprendieron 6 esta semana una desesperada búsqueda de familiares y amigos por los hospitales, centros de emergencia y tanatorios de la región. El Ministerio del Interior tailandés señaló \$ ayer que hay 5.046 muertos confirmados, incluidos 2.461 turistas, aunque redujo hasta 3.810 la cifra de desaparecidos, entre ellos al menos 1.600 extranjeros, la mayoría europeos. En los establecimientos hoteleros de las provincias de Phuket, Phang Nga y Krabi había al menos 100.000 turistas extranjeros, sobre todo europeos, cuando se produjo el maremoto, indicó el Ministerio del Interior.

\begin{tabular}{|c|c|c|c|c|c|c|c|}
\hline \multicolumn{4}{|c|}{$\begin{array}{l}\text { Fecha } \\
\text { Periódico:03/01/2005 }\end{array}$} & \multicolumn{4}{|c|}{ ORDENACIÓN DE EVENTOS } \\
\hline ID & POSI & POSF & EXPRESION & VALDATE 1 & VALTIME 1 & VALDATE2 & VALTIME2 \\
\hline 5060 & 4 & 4 & ayer & $02 / 01 / 2005$ & - & - & - \\
\hline 5061 & 164 & 165 & $\begin{array}{l}\text { esta } \\
\text { semana }\end{array}$ & $03 / 01 / 2005$ & - & $09 / 01 / 2005$ & - \\
\hline 5062 & 189 & 189 & ayer & $02 / 01 / 2005$ & - & - & - \\
\hline
\end{tabular}

Figure 5. TERSEO: Recognition and Resolution

\begin{tabular}{|l|l|}
\hline ORDEN & EVENTO \\
\hline 1 & $\begin{array}{l}\text { El Ministerio del Interior tailandés señaló ayer que hay } 5.046 \text { muertos } \\
\text { confirmados, incluidos } 2.461 \text { turistas, aunque redujo hasta } 3.810 ~ l a \\
\text { cifra de desaparecidos, entre ellos al menos } 1.600 \text { extranjeros, la } \\
\text { mayoría europeos }\end{array}$ \\
\hline 1 & $\begin{array}{l}\text { La policía tailandesa ordenó ayer a los familiares, amigos y } \\
\text { voluntarios que buscan a los miles de extranjeros desaparecidos por } \\
\text { el maremoto mantenerse fuera de las áreas afectadas, incluidos los } \\
\text { tanatorios instalados en templos }\end{array}$ \\
\hline 2 & $\begin{array}{l}\text { Cientos de occidentales, tailandeses y ciudadanos de otras naciones } \\
\text { asiáticas emprendieron esta semana una desesperada búsqueda de } \\
\text { familiares y amigos por los hospitales, centros de emergencia y } \\
\text { tanatorios de la región }\end{array}$ \\
\hline
\end{tabular}

Figure 6. TERSEO: Event Ordering

The extension of the system consisted of five main units:

- Translation Unit. This unit, using three translators (BabelFish ${ }^{3}$, FreeTranslator ${ }^{4}$ and PowerTranslator) makes an automatic translation of all the expressions in Spanish.

- Temporal Expression Debugger. These translated expressions will be

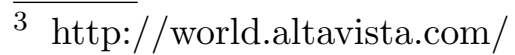

4 http://www.free-translator.com/translator3.html 


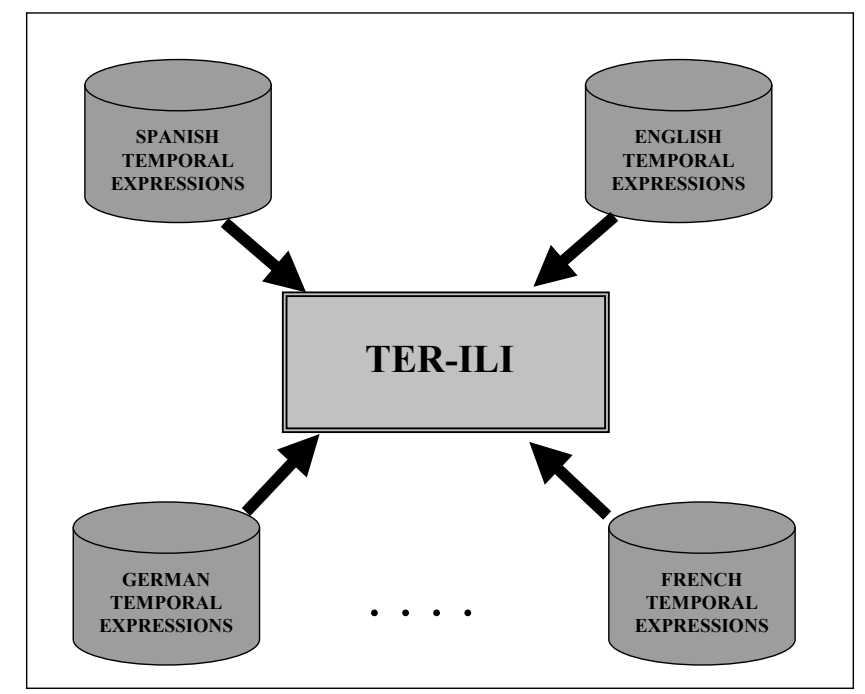

Figure 7. Schematic representation of the Temporal Expression Rules InterLingua Index

the input of the temporal expression debugger unit, that uses Google ${ }^{5}$ as a resource to eliminate those expressions that have not been translated properly. Every exact expression is searched by Google, and the expression is considered wrong if Google does not return any coincidence.

- Keyword Unit. This unit obtains a set of keywords in the target language.

- New Temporal Expression Searching Engine. This unit is able to learn new rules automatically with two different techniques:

- using WordNet to obtain synonymous expressions

- using the keywords and an un-annotated corpus in the target language

- Resolution Linker. This unit links every new rule with its resolution.

Once the system is able to work on a multilingual level, it can be used in multiple applications of Natural Language Processing (NLP) as explained in the following section.

\section{Application of Event Ordering in NLP tasks}

Event Ordering can be applied to different tasks in the field of Natural Language Processing. Some of the applications in which event ordering is useful are for example: Summarization, Question Answering, etc. In particular, we have developed a method to apply Event Ordering to Temporal Question Answering [17].

Temporal Question Answering is not a trivial task due to the complexity that

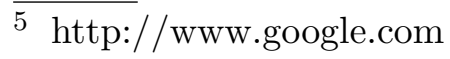


temporal questions can achieve. Current Question Answering systems can deal with simple questions requiring a date as answer, for instance: "When was the Iraq war" or questions that use explicit temporal expressions in their formulation like "Who was the president of the USA in 1988". Nevertheless, more complex questions referring to the temporal properties of the entities being questioned and their relative temporal ordering in the question are beyond the scope of current Question Answering systems. These complex questions consist of two or more events, related to a temporal signal, which establishes the order between the events in the question. This situation allows us to divide, using Temporal Signals, the complex question into simple ones, which the current Question Answering systems are able to resolve, and recompose the answer using the ordering established by the temporal signal(ordering key) to obtain a final answer to the complex question [18].

An example of the how the system works with the question: Where did Bill Clinton study before going to Oxford University? is shown here:

(1) First of all, the unit recognizes the temporal signal, which in this case is before, that corresponds with the ordering key DATE1 < DATE2.

(2) Secondly, the complex question is divided into simple ones.

- Q1: Where did Bill Clinton study?

- Q2: When did Bill Clinton go to Oxford University?

(3) A general purpose Question Answering system answers the simple questions, obtaining the following results:

- Answer for Question 1: Georgetown University (1964-1968)

- Answer for Question 1: Oxford University (1968-1970)

- Answer for Question 1: Yale Law School (1970-1973)

- Answer for Question 2: 1968

(4) All those answers that do not fulfill the constraint established by the ordering key are rejected.

(5) After that, the final answer to the complex question is Georgetown University.

\section{System evaluation}

In order to carry out the evaluation of the multilingual system a first evaluation on digital newspaper articles was perfomed. A manual annotation of texts has been made by two annotators with the purpose of comparing it with the automatic annotation that the system produces. For that reason, it is necessary to confirm that the manual information is trustworthy and it does not alter the results of the experiment. Carletta [19] explains that to assure a good annotation it is necessary to make a series of direct measurements that are: stability, reproducibility and precision, but in addition to these measure- 
ments the reliability must measure the amount of noise in the information. The authors argue that, due to the amount of agreement by chance that can be expected depends on the number of relative frequencies of the categories under test, the reliability for the classifications of categories would have to be measured using the factor kappa defined in Siegel and Castellan [20]. The factor kappa $(k)$ measures the affinity in agreement between a set of annotator when they make category judgments.

In our case, there is only one class of objects and there are three objects within this class: objects that refer to the date of the article, objects which refer to the previous date and objects that refer to another date different from the previous ones.

After carrying out the calculation, a value $k=0.953$ was obtained. According to the work of Carletta [19], a measurement of $k$ like $0,68<k<0,8$ means that the conclusions are favorable, and if $k>0,8$ means total reliability exists between the results of the two annotators that have annotated the corpora. Since our value of $k$ is greater than 0,8 , it is guaranteed that a total reliability in the conducted annotation exists and therefore, the results of obtained precision and recall are guaranteed.

In order to evaluate the event ordering method, an evaluation of the TERSEO system was carried out. The establishment of a correct order between the events implies that the resolution is correct and the events are placed on a timeline, as shown in Figure 8. For this reason, we have made an evaluation of the resolution of the Temporal Expressions.

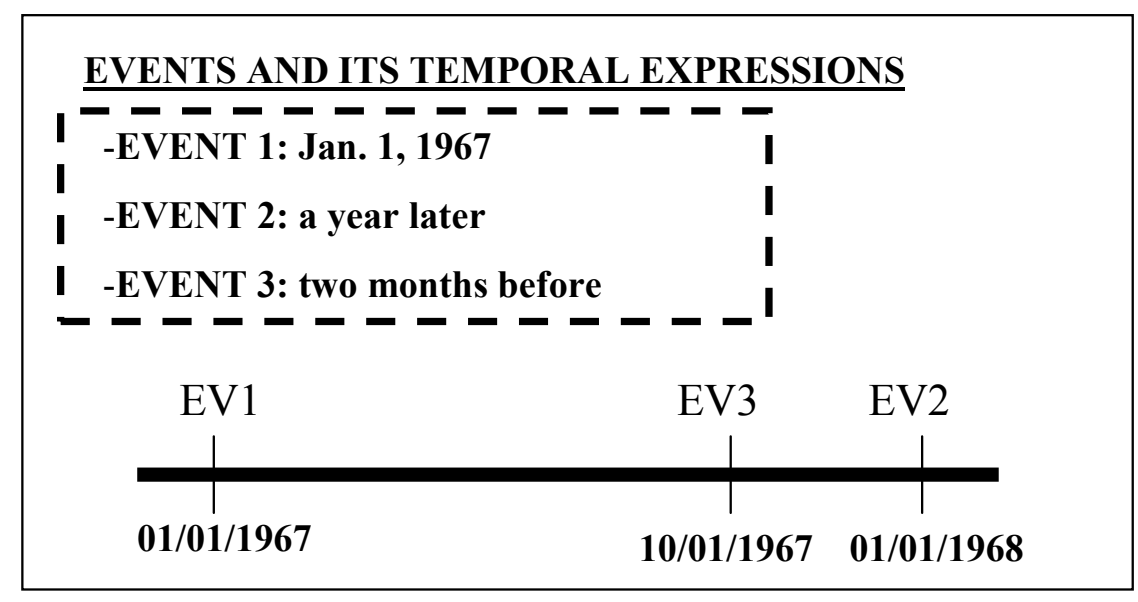

Figure 8. Event Ordering based on TE resolution

In addition, since the initial system was a monolingual system in Spanish based on knowledge, two corpora formed by newspaper articles in Spanish were used. The first set has been used for training and the second for testing after making the opportune adjustments to the system. In order to evaluate 
the English system, since the rules were obtained automatically, only the test corpus was used. The results of precision, recall and f-measure(with same relevance for precision and recall) obtained are shown in table 3.

Table 3

\begin{tabular}{|l|l|l|l|}
\hline & SPANISH & & ENGLISH \\
\hline & TRAINING & TEST & TEST \\
\hline No Art. & 50 & 50 & 100 \\
\hline Real Ref & 238 & 199 & 634 \\
\hline $\begin{array}{l}\text { Treated } \\
\text { Ref. }\end{array}$ & 201 & 156 & 511 \\
\hline Successes & 170 & 138 & 393 \\
\hline Precision & $84 \%$ & $88 \%$ & $77 \%$ \\
\hline Recall & $71 \%$ & $69 \%$ & $62 \%$ \\
\hline $\begin{array}{l}\text { F- } \\
\text { Measure }\end{array}$ & $77 \%$ & $77 \%$ & $68 \%$ \\
\hline \hline
\end{tabular}

Evaluation of the multilingual system

Although the obtained results are highly successful, we have detected some failures that have been deeply analyzed. As can be observed in the results, our system could be improved in some aspects. Below, a study of the problems detected and their possible improvements are shown:

- In newspaper articles, sometimes there are expressions like "el sábado hubo cinco accidentes" (Saturday there were five accidents). To resolve this kind of reference we need context information of the sentence where the reference is. That information could be the tense of the verb in the sentence. If the verb is a past verb, it indicates that it is necessary to solve a reference like "el sábado pasado" (last Saturday), whereas if it is a future verb it refers to "el sábado próximo" (next Saturday). Because our system does not use semantic or context information we assume this kind of reference refers to the last day, not the next, because the news usually tells us facts which occurred previously.

- Our system is not able to resolve temporal expressions that contain a wellknown event, for instance: "two days before the Olympic Games...". In order to solve this kind of expression, some extra knowledge of the world is necessary, and we are not able to access this kind of information at present.

Recently, the system has also been evaluated in the TERN conference ${ }^{6}$. TERN stands for Time Expression Recognition and Normalization Evaluation and requires systems to detect and normalize temporal expressions occurring in

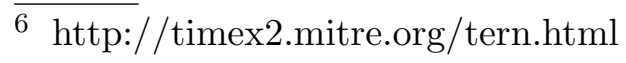


English and/or Chinese text. The Time Expression Recognition and Normalization (TERN) evaluation is based on work that began in 1999 to establish a set of useful guidelines for text annotation and data interchange. The guidelines define a tag called TIMEX2, including attributes for expressing the normalized, intended meaning or value of a broad range of temporal expressions. The work extends the Message Understanding Conferences definition of the TIMEX category of named entity to include a broader variety of expressions and to offer a normalization scheme. Our participation was in English and we have obtained the results shown in Tables 4 and 5.

Table 4

\begin{tabular}{|l|l|l|}
\hline \multirow{2}{*}{ SOURCE } & REF & VALUE \\
\cline { 2 - 3 } & $\#$ & $\mathbf{( \% )}$ \\
\hline $\begin{array}{l}\text { Broadcast } \\
\text { News }\end{array}$ & 986 & 61.2 \\
\hline Newswire & 842 & 43.7 \\
\hline Combined & $\mathbf{1 8 2 8}$ & $\mathbf{5 3 . 1}$ \\
\hline \hline
\end{tabular}

Overall cost performance

Table 5

\begin{tabular}{|l|l|l|l|l|}
\hline \multirow{2}{*}{ ATTRIBUTE } & REF & PREC & REC & F \\
\cline { 2 - 5 } & $\#$ & $\mathbf{\%}$ & $\mathbf{\%}$ & $\mathbf{\%}$ \\
\hline ANCHOR_DIR & 305 & 86.4 & 59.2 & 70.2 \\
\hline ANCHOR_VAL & 305 & 63.9 & 43.8 & 51.9 \\
\hline MOD & 36 & 50.0 & 12.5 & 20.0 \\
\hline SET & 1437 & 99.3 & 99.3 & 99.3 \\
\hline VAL & 1391 & 82.8 & 85.5 & 84.2 \\
\hline EXTENT (text) & 1437 & 85.9 & 85.9 & 85.9 \\
\hline \hline
\end{tabular}

Attribute recognition statistics for combined sources

In this evaluation, the output of our system needed to be transformed to the TIMEX2 tags. The attributes of the TIMEX2 tags are shown in Table 6.

Some errors in this evaluation were due to the adaptation of the output because the attributes of our tags are different from the TIMEX2 ones. Our annotation scheme is more focused on establishing concrete dates or range of dates without modifiers, because this kind of annotation allows us to establish an easier event ordering method than using TIMEX2 annotation scheme. Moreover, our system in English has been automatically extended and all the rules are automatically obtained, but results will be better after manually tuning the system. 


\begin{tabular}{|l|l|l|}
\hline Tag & Definition & Example \\
\hline VAL & $\begin{array}{l}\text { Contains a form of the } \\
\text { date/time. }\end{array}$ & $\begin{array}{l}\text { VAL= "1964-10-1" (e.g., for } \\
\text { "October 16, 1964") }\end{array}$ \\
\hline MOD & $\begin{array}{l}\text { Captures temporal modi- } \\
\text { fiers. }\end{array}$ & $\begin{array}{l}\text { MOD= "APPROX" (e.g., } \\
\text { "about 5 o'clock") }\end{array}$ \\
\hline ANCHOR_VAL & $\begin{array}{l}\text { Contains a normalized form } \\
\text { of an anchoring date/time. }\end{array}$ & $\begin{array}{l}\text { ANCHOR_VAL="1964-10- } \\
16 " \text { (e.g., "he was in Vietnam } \\
\text { for six months prior to Octo- } \\
\text { ber 16, 1964". Would be used } \\
\text { in conjuntion with a VAL of } \\
\text { P6M.) }\end{array}$ \\
\hline ANCHOR_DIR & $\begin{array}{l}\text { Captures the relative direc- } \\
\text { tion/ orientation between } \\
\text { VAL and ANCHOR_VAL. }\end{array}$ & ANCHOR_DIR="BEFORE" \\
\hline ANCHOR_DIR & $\begin{array}{l}\text { Identifies expressions de- } \\
\text { noting sets of times. }\end{array}$ & SET= "YES" \\
\hline \hline
\end{tabular}

Table 6

TIMEX2 attributes

\section{Conclusions}

In this article a method of event ordering using temporal information has been presented. This method is based on the detection of keywords (temporal signals) and the resolution of the temporal information associated to the event. This method can be applied to multilingual texts because TERSEO system is able to work on a multilingual level. As an application, this tool can be used to improve other NLP systems, for example: Question Answering systems, with questions of temporal information or Summarization systems. At present, an application of this work is being used with the Question Answering system [21]. Two different evaluations have been presented in this paper as well as successful results for precision and recall and it is very important to emphasize that the English knowledge database was automatically obtained from the Spanish one.

As future work, two tasks will be considered:

- The system will cope with the resolution of temporal expressions considering context information or world knowledge.

- English knowledge database will be tuned manually in order to improve the results for this language and to use this new database as a base for the extension of the system to other languages (French, German, ...). In order to do this, a previous study of temporal information in English must be done. 


\section{References}

[1] D. Radev, B. Sundheim, Using timeml in question answering, Tech. rep., ARDA, Brandeis University (2002).

[2] A. Setzer, R. Gaizauskas, Annotating events and temporal information in newswire texts, in: LREC [22].

[3] A. Setzer, R. Gaizauskas, Building a temporally annotated corpus for information extraction, in: LREC [22].

[4] D. Radev, B. Sundheim, Using timeml in question answering, http://www.cs.brandeis.edu/ jamesp/ arda/ time/ (2002).

[5] E. Filatova, E. Hovy, Assigning time-stamps to event-clauses, in: ACL [23], pp. $88-95$.

[6] F. Schilder, C. Habel, From temporal expressions to temporal information: Semantic tagging of news messages, in: ACL [23], pp. 65-72.

[7] G. Katz, F.Arosio, The annotation of temporal information in natural language sentences, in: ACL [23], pp. 104-111.

[8] A. Setzer, R. Gaizauskas, On the importance of annotating event-event temporal relations in text, in: LREC (Ed.), Proceedings of the LREC Workshop on Temporal Annotation Standards, 2002, Las Palmas de Gran Canaria,Spain, 2002, pp. 52-60.

[9] E. Saquete, P. Martínez-Barco, R. Muñoz, Automatic multilinguality for time expression resolution, in: MICAI (Ed.), Proceedings Mexican International Conference on Artificial Intelligence, Mexico D.F., Mexico, 2004, pp. 458-467.

[10] R. Muñoz, A. Montoyo, F. Llopis, A. Suárez, Reconocimiento de entidades en el sistema EXIT, Procesamiento del Lenguaje Natural 23 (1998) 47-53.

[11] E. Saquete, R. Muñoz, P. Martínez-Barco, Terseo: Temporal expression resolution system applied to event ordering, in: TSD (Ed.), Proceedings of the 6th International Conference ,TSD 2003, Text, Speech and Dialogue, Ceske Budejovice,Czech Republic, 2003, pp. 220-228.

[12] R. Muñoz, A. Ferrández, P. Martínez-Barco, Método para la resolución de correferencias de sintagmas nominales definidos incluyendo alias y acrónimos en el sistema de extracción de información EXIT, Procesamiento del Lenguaje Natural 25 (1999) 143-149.

[13] P. Martínez-Barco, Algoritmo de resolución de la anáfora pronominal en diálogos, Procesamiento del Lenguaje Natural 24 (1999) 75-82.

[14] P. Martínez-Barco, M. Palomar, Resolución de la anáfora: estructura del diálogo y conocimiento lingüístico, Procesamiento del Lenguaje Natural 26 (2000) 4752 . 
[15] G. Wilson, I. Mani, B. Sundheim, L. Ferro, A multilingual approach to annotating and extracting temporal information, in: ACL [23], pp. 81-87.

[16] G. A. Miller, Wordnet: a lexical database for english.

[17] E. Saquete, P. Martínez-Barco, R. Muñoz, J. Vicedo, Splitting complex temporal questions for question answering systems, in: ACL [21].

[18] E. Saquete, P. Martínez-Barco, R. Muñoz, J. Vicedo, Multilayered question answering system applied to temporality evaluation, Procesamiento del Lenguaje Natural 33 (2004) 25-32.

[19] J. Carletta, et al., The reliability of a dialogue structure coding scheme, Computational Linguistics 23 (1) (1997) 13-32.

[20] S. Siegel, J. Castellan, Nonparametric Statistics for the Behavioral Sciences, 2nd Edition, McGraw-Hill, 1988.

[21] ACL (Ed.), 42nd Annual Meeting of the Association for Computational Linguistics, Barcelona, España, 2004.

[22] LREC (Ed.), Proceedings of the Information Extraction Meets Corpus Linguistic, LREC 2000, Athens, Greece, 2000.

[23] ACL (Ed.), Proceedings of the 2001 ACL-EACL, Workshop on Temporal and Spatial Information Processing, Toulouse,France, 2001. 